DOI: https://dx.doi.org/10.26808/rs.ca.i8v1.07

International Journal of Computer Application (2250-1797)

Issue 8 Volume 1, January- February 2018

\title{
Nonlinear Autoregression Neural Network for Meteorological Parameters Forecasting to Evaluate the Behavior of Radioactive Material Release from Nuclear Power Plants
}

\author{
Eman Sarwat \\ Radiation Safety Department, Nuclear and Radiological Regulatory Authority (NRRA)
}

\begin{abstract}
In this paper a Nonlinear Autoregression Neural Network with exogenous input (NARX) is used to forecast temperature and wind speed. Six cases are studied to find the best condition with minimum mean absolute percentage error (MAPR) for prediction. In the first three cases the input data to NARX are four meteorological parameters (time, dew point, pressure and humidity) and the outputs are two parameters (temperature (Temp.) and wind speed (W.S.)). The first case is tested for Temp. and W.S. together as outputs. The second and the third cases are tested for Temp. and W.S. respectively. The results show that the first case gives MAPE for forecasting the two parameters together less than considering each one separately. As a result the first case is taken as a basic approach to the following three cases. In the fourth, fifth and sixth cases the input to NARX is taken as three parameters only without (dew point, pressure and humidity) respectively in each case. The NARX outputs are two parameters (Temp. and W.S.). In the last three cases the MAPE in the output parameters when compared with practical measurement of meteorological parameters do not exceed 20\%. These results confirm that NARX model used in the current paper have the potential for successful application to meteorological parameters forecasting. NARX based weather forecast shows improvement over guidance forecasts from numerical models and official local weather.
\end{abstract}

Keywords: Temperature and wind speed forecasting, Nonlinear Autoregression, Artificial Neural Network.

\section{INTRODUCTION}

In the last few decades weather forecasting has become an important field of research. In most of the cases the researcher had attempted to create a linear relationship between the input weather data and the corresponding goal data. But with the discovery of nonlinearity in the nature of weather data, the focus has shifted towards the nonlinear prediction of the weather data [1].

Since the weather data is nonlinear and follows a very irregular trend, Nonlinear Autoregression Neural Network with exogenous input (NARX) has evolved out to be a better technique to bring out the structural relationship between the various entities [2\&3].

There are three methodologies that have been used for W.S. and Temp. prediction. The first methodology is based on statistical models that characterize the correlation structure in measured W.S. and Temp. Time series analysis models such as the autoregressive (AR) models, moving average (MA) models, and autoregressive integrated moving average (ARIMA) models have been applied to these types of historical data. Erdem and Shi [4] and Torres et al. [5] used an ARIMA model for forecasting the wind speed and direction.

The second methodology consists of using a physics-based (weather) forecasting model for W.S. and Temp prediction [6].

The third methodology for W.S. and Temp. forecasting utilizes machine learning approaches. Within this class of methods, artificial neural network (ANN), fuzzy systems theory, and other related paradigms 
DOI: https://dx.doi.org/10.26808/rs.ca.i8v1.07 International Journal of Computer Application (2250-1797) Issue 8 Volume 1, January- February 2018

such as grey predictors and support vector machine (SVM) have been applied. Damousis and Dokopoulos [7], Damousis et al. [8], and Pinson and Kariniotakis [9-11] used fuzzy model expert systems for W.S. and Temp. forecasting, whereby the relationship between the independent and dependent variables is described by a fuzzy mapping system. ANN has been also widely applied to characterize the relationship between W.S. and Temp. [12].

In this paper, we propose a new methodology for forecasting wind speed and wind turbine power. The approach uses a numerical weather prediction model to specify the boundary conditions for a highresolution NARX model to make predictions of the W.S. and Temp.. The time, pressure, wet point and humidity information is then used as the exogenous input to a nonlinear autoregressive (NARX) that are trained and subsequently used for forecasting of the W.S. and Temp.. This paper is organized as follows. Section 2, introduces the methodology used for network training and data evaluation. Section 3, presents results and discussion for wind speed and temperature forecasting, compares these forecasted values to the actual measured values. While Section 4, provides the conclusion of the paper.

\section{METHODOLOGY}

The NARX models are commonly used in the system of identification area [13]. The nonlinear autoregressive network with exogenous inputs (NARX) is a recurrent dynamic network, with feedback connections enclosing several layers of the network. The NARX model is based on the linear ARX model, which is commonly used in time-series modeling.

Figure 1 illustrates the standard NARX network. The standard NARX network used here is a two-layer feedforward network, with a sigmoid transfer function in the hidden layer and a linear transfer function in the output layer. This network also uses tapped delay lines (d) to store previous values of the input, $x(t)$ and output, $y(t)$ sequences. First, load the training data and use tapped delay lines with two delays for both the input and the output, so training begins with the third data point. There are two inputs to the series-parallel network, the $\mathrm{x}(\mathrm{t})$ sequence and the $\mathrm{y}(\mathrm{t})$ sequence [14-16].

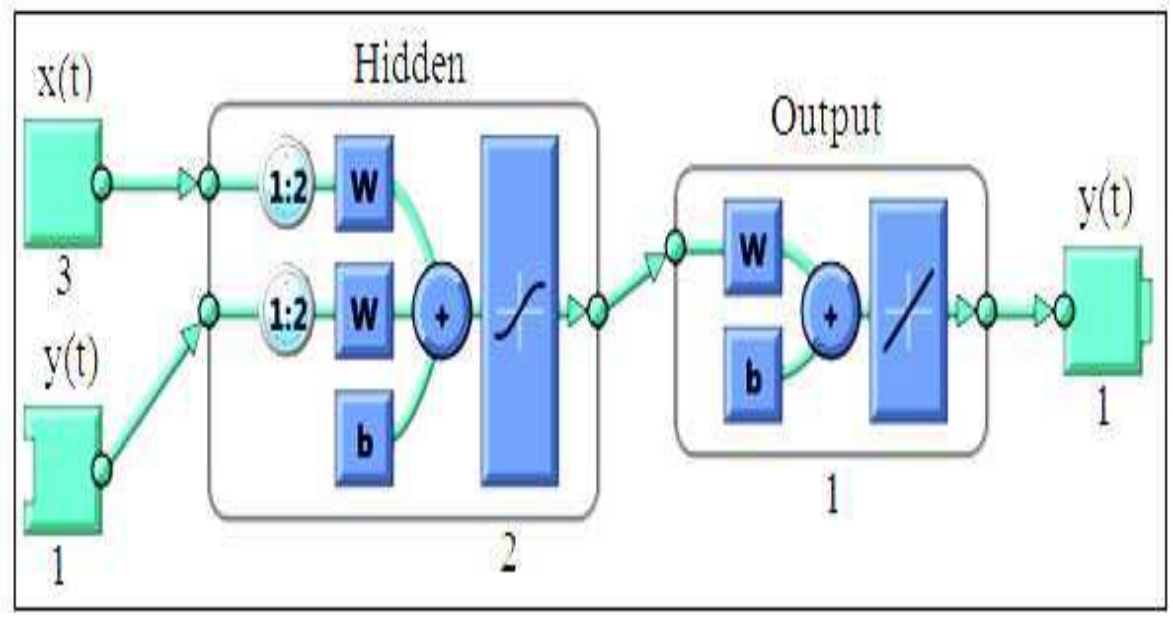

Fig. 1: NARX Network

$\mathrm{y}(\mathrm{t})$ sequence is considered a feedback signal, which is an input that is also an output (target). The model can be shown in the following equation:

$y(t)=f(y(t-1), \ldots, y(t-d), x(t-1), \ldots,(t-d))$ 
DOI: https://dx.doi.org/10.26808/rs.ca.i8v1.07

where, $y(t)$ is the output of the NARX network and also feedback to the input of the network and tapped delay lines $(\mathrm{d})$ that store the previous values of $\mathrm{x}(\mathrm{t})$ and $\mathrm{y}(\mathrm{t})$ sequences. It also has been reported that gradient descent learning can be more effective in NARX networks than in other recurrent architecture [17-20].

\subsection{Metrological Parameters Forecasting}

This study evaluates the utility of NARX for Forecasting hourly surface temperature (Temp.) and Wind Speed (W.S.). Manipulative NARX model follows a number of systemic dealings. In general, there are three basics steps: (1) collecting weather data to train NARX with part of the input (hourly dew point, humidity and pressure), the temp. and W.S. as the output data, (2) preprocessing data in order to test the NARX forecasting of temp. and W.S. with the remaining data, (3) construction the NARX network model. The basic flow chart in designing NARX model is given in Figure 2 [16]. The weather data used in this study for 12 hours (12 AM until 11 AM) are collected from the Aceanic and Atmospheric Admen Administration (Noaa) for Late North Coast of Egypt [21]. Separate six cases with different weather parameters for NARX input and output are built to predict both temperature and wind speed. The accuracy results between the actual and predicted values are evaluated using percentage error and MAPE.

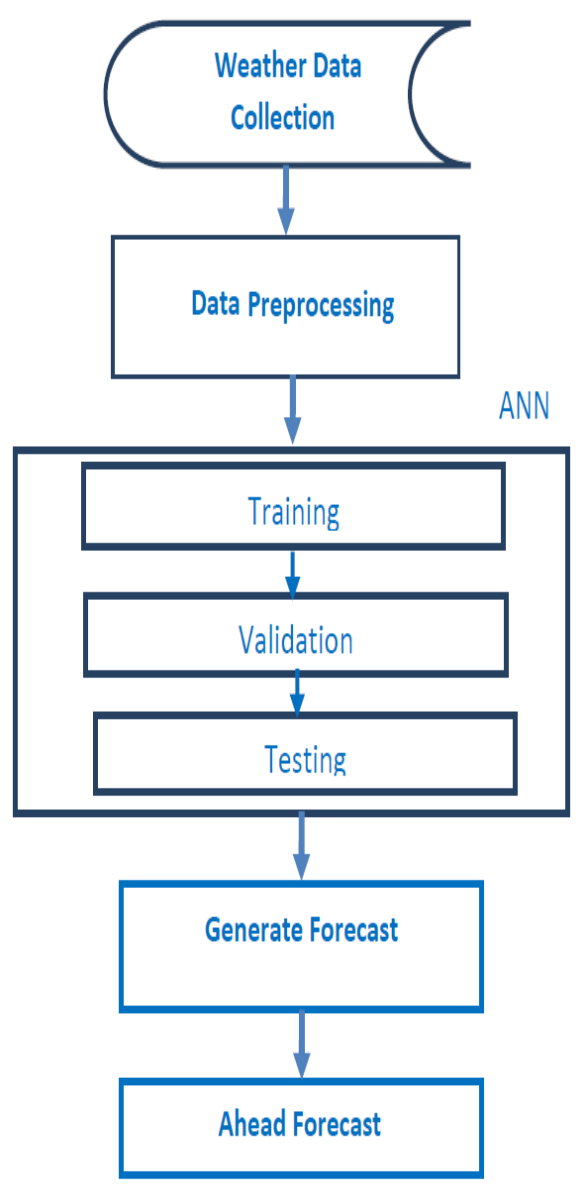

Fig. 2: Designing NARX Model for Weather Forecast 
DOI: https://dx.doi.org/10.26808/rs.ca.i8v1.07 International Journal of Computer Application (2250-1797) Issue 8 Volume 1, January- February 2018

\section{Data used for present study}

\section{RESULTS AND DISCUSSION}

In this study, we used hourly temperature, humidity, dew point, pressure and wind speed which are collected from Noaa for Late North Coast of Egypt [21]. The total number of observations is 12 data covered from 12 AM until $11 \mathrm{AM}$ as shown in table 1.

The following part will discuss six cases study with different conditions for input and output data. Also the percentage error between the actual and forecasting results using NARX is illustrated in all cases study as shown from table 2 till table 9 . Except table 5 and 9 which indicates the MAPE for cases studied.

Table 1: Methodological weather parameters for Late North Coast of Egypt

\begin{tabular}{|c|c|c|c|}
\hline Time [hourly] & Dew Point $\left[{ }^{\mathbf{}} \mathbf{C}\right]$ & Humidity [\%] & Pressure [hPa] \\
\hline $12 \mathrm{AM}$ & 5 & 45 & 1014 \\
\hline $1 \mathrm{AM}$ & 6 & 52 & 1014 \\
\hline $2 \mathrm{AM}$ & 6 & 52 & 1014 \\
\hline $3 \mathrm{AM}$ & 6 & 52 & 1014 \\
\hline $4 \mathrm{AM}$ & 6 & 52 & 1015 \\
\hline $5 \mathrm{AM}$ & 6 & 55 & 1015 \\
\hline $6 \mathrm{AM}$ & 6 & 55 & 1015 \\
\hline $7 \mathrm{AM}$ & 7 & 59 & 1015 \\
\hline $8 \mathrm{AM}$ & 5 & 48 & 1016 \\
\hline $9 \mathrm{AM}$ & 9 & 52 & 1017 \\
\hline $10 \mathrm{AM}$ & 10 & 49 & 1017 \\
\hline $11 \mathrm{AM}$ & 11 & 44 & 1017 \\
\hline
\end{tabular}

Case 1:In this case, NARX has four inputs (Time, Dew point, Pressure and Humidity) as illustrated in table 1 and the outputs are the temperature and wind speed together. NARX are trained with input and output data from $12 \mathrm{AM}$ to $6 \mathrm{AM}$, then the NARX forecasts from 7 AM to 11 AM. The forecasting results for temp. and W.S. are illustrated in table 2.

Table 2: Forecasting temperature and wind speed in case of four inputs (Time, Dew point, Pressure and Humidity)

\begin{tabular}{|c|c|c|c|c|c|c|}
\hline \multirow{2}{*}{$\begin{array}{c}\text { Time } \\
\text { [hourly] }\end{array}$} & \multicolumn{2}{|c|}{ Temperature $\left[{ }^{\circ} \mathrm{C}\right]$} & \multirow{2}{*}{$\begin{array}{c}\text { Percentage Error } \\
\text { of Temp. [\%] }\end{array}$} & \multicolumn{2}{|c|}{ Wind Speed [km/hr] } & \multirow{2}{*}{$\begin{array}{c}\text { Percentage Error of } \\
\text { W.S. [\%] }\end{array}$} \\
\hline & Actual & Predicted & & Actual & Predicted & \\
\hline $12 \mathrm{AM}$ & 17 & 15.1341 & 10.9754 & 14.8 & 14.6413 & 1.0717 \\
\hline $1 \mathrm{AM}$ & 16 & 15.9254 & 0.4657 & 11.1 & 13.1122 & 18.1280 \\
\hline $2 \mathrm{AM}$ & 16 & 15.9269 & 0.4565 & 18.5 & 18.7849 & 1.5405 \\
\hline $3 \mathrm{AM}$ & 16 & 15.8372 & 1.0172 & 18.5 & 18.5510 & 0.2759 \\
\hline $4 \mathrm{AM}$ & 16 & 15.7567 & 1.5201 & 16.7 & 17.2947 & 3.5611 \\
\hline $5 \mathrm{AM}$ & 15 & 15.1096 & 0.7308 & 18.5 & 18.1314 & 1.9923 \\
\hline $6 \mathrm{AM}$ & 15 & 15.0952 & 0.6348 & 18.5 & 18.1627 & 1.8227 \\
\hline $7 \mathrm{AM}$ & 15 & 18.1318 & 20.8790 & 16.7 & 16.4261 & 1.6397 \\
\hline $8 \mathrm{AM}$ & 16 & 18.0971 & 13.1069 & 18.5 & 16.5916 & 10.3153 \\
\hline $9 \mathrm{AM}$ & 19 & 18.1327 & 4.5643 & 14.8 & 16.4276 & 10.9976 \\
\hline $10 \mathrm{AM}$ & 21 & 18.1327 & 13.6534 & 14.8 & 16.4276 & 10.9976 \\
\hline $11 \mathrm{AM}$ & 24 & 18.1327 & 24.4467 & 14.8 & 16.4276 & 10.9976 \\
\hline
\end{tabular}


DOI: https://dx.doi.org/10.26808/rs.ca.i8v1.07 International Journal of Computer Application (2250-1797)

Issue 8 Volume 1, January- February 2018

Cases $2 \&$ 3:In these cases, the inputs to NARX are four (Time, Dew point, Pressure and Humidity) as illustrated in table 1 . The NARX output is the temperature only in case 2 as shown in table 3 , while in case 3 the wind speed is the output only as shown in table 4 .

Table 3: Temperature forecasting in case of four inputs (Time, Dew point, Pressure and Humidity)

\begin{tabular}{|c|c|c|c|}
\hline \multirow{2}{*}{ Time [hourly] } & \multicolumn{2}{|c|}{ Temperature [ ${ }^{\mathbf{0}}$ ] } & \multirow{2}{*}{ Percentage Error [\%] } \\
\cline { 2 - 3 } & Actual & Predicted & 9.3347 \\
\hline $12 \mathrm{AM}$ & 17 & 15.4130 & 3.3504 \\
\hline $1 \mathrm{AM}$ & 16 & 16.5360 & 3.3413 \\
\hline $2 \mathrm{AM}$ & 16 & 16.5346 & 3.2487 \\
\hline $3 \mathrm{AM}$ & 16 & 16.5198 & 0.5410 \\
\hline $4 \mathrm{AM}$ & 16 & 15.9134 & 8.6956 \\
\hline $5 \mathrm{AM}$ & 15 & 16.3043 & 5.2219 \\
\hline $6 \mathrm{AM}$ & 15 & 15.7832 & 8.7907 \\
\hline $7 \mathrm{AM}$ & 15 & 16.3186 & 10.0204 \\
\hline $8 \mathrm{AM}$ & 16 & 17.6032 & 3.3212 \\
\hline $9 \mathrm{AM}$ & 19 & 18.3689 & 12.4616 \\
\hline $10 \mathrm{AM}$ & 21 & 18.3830 & 24.6546 \\
\hline $11 \mathrm{AM}$ & 24 & 18.0828 & \\
\hline
\end{tabular}

Table 4: Wind speed forecasting in case of four inputs (Time, Dew point, Pressure and Humidity)

\begin{tabular}{|c|c|c|c|}
\hline \multirow{2}{*}{ Time [hourly] } & \multicolumn{2}{|c|}{ Wind Speed [km/hr] } & \multirow{2}{*}{ Percentage Error [\%] } \\
\cline { 2 - 3 } & Actual & Predicted & 0.3512 \\
\hline $12 \mathrm{AM}$ & 14.8 & 14.7480 & 35.8308 \\
\hline $1 \mathrm{AM}$ & 11.1 & 15.0772 & 0.4660 \\
\hline $2 \mathrm{AM}$ & 18.5 & 18.4137 & 18.2672 \\
\hline $3 \mathrm{AM}$ & 18.5 & 15.1205 & 2.8638 \\
\hline $4 \mathrm{AM}$ & 16.7 & 17.1782 & 4.1197 \\
\hline $5 \mathrm{AM}$ & 18.5 & 17.7378 & 5.4760 \\
\hline $6 \mathrm{AM}$ & 18.5 & 17.4869 & 9.1249 \\
\hline $7 \mathrm{AM}$ & 16.7 & 15.1761 & 22.1252 \\
\hline $8 \mathrm{AM}$ & 18.5 & 22.5931 & 26.3652 \\
\hline $9 \mathrm{AM}$ & 14.8 & 18.7020 & 26.3556 \\
\hline $10 \mathrm{AM}$ & 14.8 & 18.7006 & 26.3085 \\
\hline $11 \mathrm{AM}$ & 14.8 & 18.6936 & \\
\hline
\end{tabular}

\section{Comparison between cases 1, 2 and 3:}

The MAPE is calculated for the above three cases and the results are illustrated in table 5. The results indicates that the MAPE in case 1 in which the outputs are the Temp. and W.S. together are 7.7 and 6.1 respectively. While the MAPE in case 2 in which the output is the Temp. only is 7.74. Also the MAPE of case 3 in which the output is the W.S. only is 14.8, this indicates that the results in case 2 and 3 are not good as the first case. As a result the first case will be taken as a basic approach for the following cases study (from case 4 till case 6). 
DOI: https://dx.doi.org/10.26808/rs.ca.i8v1.07 International Journal of Computer Application (2250-1797)

Issue 8 Volume 1, January- February 2018

Table 5: Mean Absolute Percentage Error (MAPE) in case of four inputs (Time, Dew point, Pressure and Humidity) and two outputs first temperature and wind speed together then each one separately

\begin{tabular}{|c|c|c|}
\hline \multirow{2}{*}{ Case Study } & \multicolumn{2}{|c|}{ MAPE } \\
\cline { 2 - 3 } & Temperature (Temp.) & Wind speed (W.S) \\
\hline Case 1 (Temp. and W.S) & 7.7042 & 6.1117 \\
\hline Case 2 (Temp.) & 7.7485 & - \\
\hline Case 3 (W.S) & - & 14.8045 \\
\hline
\end{tabular}

Figure 3 shows Comparisons between actual and forecasted data for Temp. and W.S. together then each one separately using NARX. It is observed that it is better to forecast Temp. and W.S. together and take them as a basis for the following cases study.

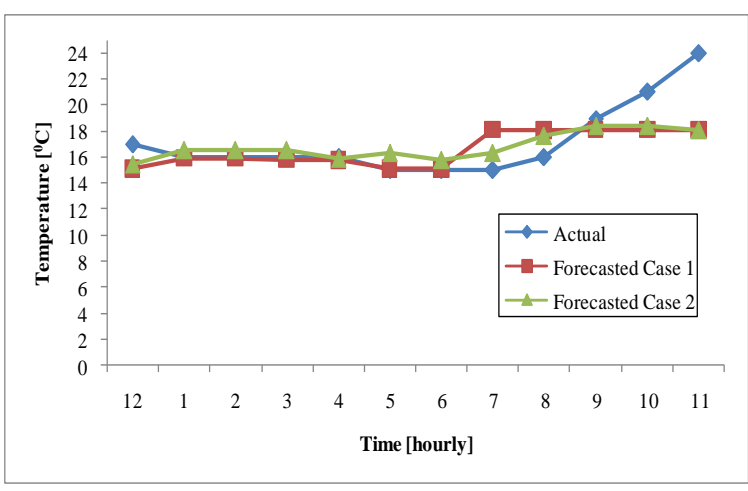

(a) Temperature

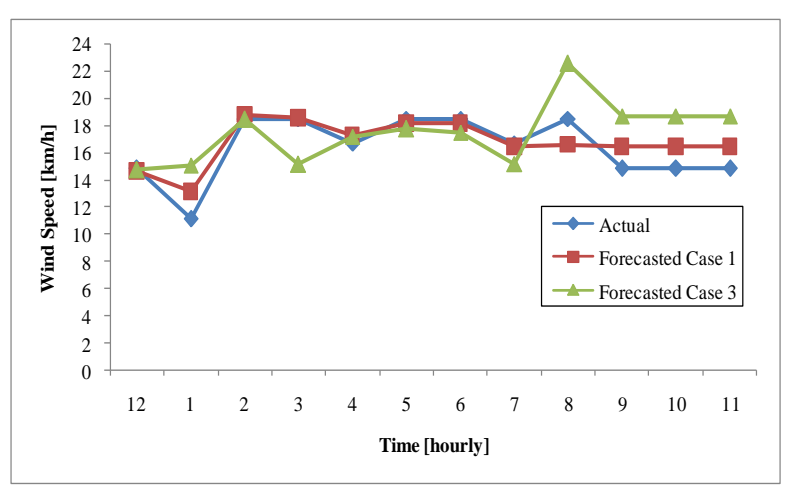

(b) Wind Speed

Fig. 3: Comparison between actual and forecasted values for (a) Temp. and (b) W.S. in cases 1, 2 and 3

Case 4:In this case, the forecasted Temp. and W.S. are the outputs of NARX and the inputs to NARX are three parameters without dew point.

Table 6: Temperature and wind speed in case of three inputs (Time, Pressure and Humidity)

\begin{tabular}{|c|c|c|c|c|c|c|}
\hline \multirow{2}{*}{$\begin{array}{c}\text { Time } \\
{[\text { hourly }]}\end{array}$} & \multicolumn{2}{|c|}{ Temperature [ $\left.{ }^{\mathbf{0}} \mathbf{C}\right]$} & \multirow{2}{*}{$\begin{array}{c}\text { Percentage Error } \\
\text { of Temp. [\%] }\end{array}$} & \multicolumn{2}{|c|}{ Wind Speed [km/hr] } & Percentage Error \\
& Actual & Predicted & Actual & Predicted & of.S. [\%] \\
\hline 12 AM & 17 & 16.7669 & 1.3707 & 14.8 & 11.9862 & 19.0120 \\
\hline 1 AM & 16 & 16.7533 & 4.7081 & 11.1 & 12.1701 & 9.6405 \\
\hline 2 AM & 16 & 16.4385 & 2.7409 & 18.5 & 15.1868 & 17.9089 \\
\hline 3 AM & 16 & 16.5728 & 3.5801 & 18.5 & 11.8189 & 36.1140 \\
\hline 4 AM & 16 & 16.4450 & 2.7816 & 16.7 & 17.5487 & 5.0821 \\
\hline 5 AM & 15 & 16.5000 & 10.0005 & 18.5 & 16.6263 & 10.1281 \\
\hline 6 AM & 15 & 16.1654 & 7.7694 & 18.5 & 16.2458 & 12.1844 \\
\hline 7 AM & 15 & 15.9281 & 6.1876 & 16.7 & 14.8296 & 11.1994 \\
\hline 8 AM & 16 & 18.5491 & 15.9322 & 18.5 & 17.7216 & 4.2074 \\
\hline 9 AM & 19 & 18.5600 & 2.3157 & 14.8 & 17.7161 & 19.7037 \\
\hline 10 AM & 21 & 18.5600 & 11.6186 & 14.8 & 17.7166 & 19.7070 \\
\hline 11 AM & 24 & 18.5600 & 22.6664 & 14.8 & 17.7196 & 19.7272 \\
\hline
\end{tabular}


DOI: https://dx.doi.org/10.26808/rs.ca.i8v1.07 International Journal of Computer Application (2250-1797)

Issue 8 Volume 1, January- February 2018

Case 5:In this case, the forecasted Temp. and W.S. are the outputs to NARX while the inputs to NARX are three parameters without humidity as illustrated in table 7.

Table 7: Temperature and wind speed in case of four inputs (Time, Dew point and Pressure)

\begin{tabular}{|c|c|c|c|c|c|c|}
\hline \multirow{2}{*}{$\begin{array}{c}\text { Time } \\
\text { [hourly] }\end{array}$} & \multicolumn{2}{|c|}{ Temperature $\left[{ }^{\circ} \mathrm{C}\right]$} & \multirow{2}{*}{$\begin{array}{c}\text { Percentage Error } \\
\text { of Temp. [\%] }\end{array}$} & \multicolumn{2}{|c|}{ Wind Speed [km/hr] } & \multirow{2}{*}{$\begin{array}{c}\text { Percentage Error } \\
\text { of W.S. [\%] }\end{array}$} \\
\hline & Actual & Predicted & & Actual & Predicted & \\
\hline $12 \mathrm{AM}$ & 17 & 12.8516 & 24.4021 & 14.8 & 13.5605 & 8.3745 \\
\hline $1 \mathrm{AM}$ & 16 & 17.4598 & 9.1241 & 11.1 & 22.0783 & 98.9035 \\
\hline $2 \mathrm{AM}$ & 16 & 17.4718 & 9.1987 & 18.5 & 20.5953 & 11.3260 \\
\hline $3 \mathrm{AM}$ & 16 & 17.4993 & 9.3710 & 18.5 & 20.7423 & 12.1209 \\
\hline $4 \mathrm{AM}$ & 16 & 17.1767 & 7.3546 & 16.7 & 18.8757 & 13.0283 \\
\hline $5 \mathrm{AM}$ & 15 & 16.7951 & 11.9679 & 18.5 & 18.1732 & 1.7662 \\
\hline $6 \mathrm{AM}$ & 15 & 16.4218 & 9.4790 & 18.5 & 17.1789 & 7.1410 \\
\hline $7 \mathrm{AM}$ & 15 & 18.9432 & 26.2881 & 16.7 & 15.1971 & 8.9989 \\
\hline $8 \mathrm{AM}$ & 16 & 14.3395 & 10.3777 & 18.5 & 16.3416 & 11.6665 \\
\hline $9 \mathrm{AM}$ & 19 & 20.5194 & 7.9968 & 14.8 & 16.0980 & 8.7706 \\
\hline $10 \mathrm{AM}$ & 21 & 20.5191 & 2.2896 & 14.8 & 16.0975 & 8.7671 \\
\hline $11 \mathrm{AM}$ & 24 & 20.5110 & 14.5371 & 14.8 & 16.0913 & 8.7255 \\
\hline
\end{tabular}

\section{Case 6:}

The inputs to NARX in this case are (time, Dew point and Humidity) without the pressure. Also NARX gives the forecasting values for Temp. and W.S. as shown in table 8.

Table 8: Temperature and wind speed in case of three inputs (Time, Dew point and Humidity)

\begin{tabular}{|c|c|c|c|c|c|c|}
\hline \multirow{2}{*}{$\begin{array}{c}\text { Time } \\
\text { [hourly] }\end{array}$} & \multicolumn{2}{|c|}{ Temperature $\left[{ }^{\circ} \mathrm{C}\right]$} & \multirow{2}{*}{$\begin{array}{c}\text { Percentage Error } \\
\text { of Temp. [\%] }\end{array}$} & \multicolumn{2}{|c|}{ Wind Speed [km/hr] } & \multirow{2}{*}{$\begin{array}{c}\text { Percentage Error } \\
\text { of W.S. [\%] }\end{array}$} \\
\hline & Actual & Predicted & & Actual & Predicted & \\
\hline $12 \mathrm{AM}$ & 17 & 14.0900 & 17.1172 & 14.8 & 19.8548 & 34.1542 \\
\hline $1 \mathrm{AM}$ & 16 & 15.8182 & 1.1360 & 11.1 & 15.0219 & 35.3331 \\
\hline $2 \mathrm{AM}$ & 16 & 15.7049 & 1.8442 & 18.5 & 16.3112 & 11.8311 \\
\hline $3 \mathrm{AM}$ & 16 & 15.6140 & 2.4122 & 18.5 & 16.0166 & 13.4236 \\
\hline $4 \mathrm{AM}$ & 16 & 15.5490 & 2.8185 & 16.7 & 16.6531 & 0.2803 \\
\hline $5 \mathrm{AM}$ & 15 & 15.2569 & 1.7131 & 18.5 & 17.7620 & 3.9890 \\
\hline $6 \mathrm{AM}$ & 15 & 15.3912 & 2.6080 & 18.5 & 17.6041 & 4.8424 \\
\hline $7 \mathrm{AM}$ & 15 & 17.9259 & 19.5065 & 16.7 & 18.8672 & 12.9777 \\
\hline $8 \mathrm{AM}$ & 16 & 14.3198 & 10.5007 & 18.5 & 19.8851 & 7.4870 \\
\hline $9 \mathrm{AM}$ & 19 & 18.7838 & 1.1374 & 14.8 & 17.7939 & 20.2293 \\
\hline $10 \mathrm{AM}$ & 21 & 18.7839 & 10.5527 & 14.8 & 17.7939 & 20.2291 \\
\hline $11 \mathrm{AM}$ & 24 & 18.7839 & 21.7336 & 14.8 & 17.7938 & 20.2288 \\
\hline
\end{tabular}

\section{Comparison between cases 4,5 and 6:}

Table 9 illustrates the MAPE results for Temp. and W.S. for three conditions : First in case of three inputs without pressure, second without dew point and finally without humidity. 
DOI: https://dx.doi.org/10.26808/rs.ca.i8v1.07 International Journal of Computer Application (2250-1797)

Issue 8 Volume 1, January- February 2018

Table 9: Mean Absolute Percentage Error for Temp. and W.S. in cases 4, 5 and 6

\begin{tabular}{|c|c|c|}
\hline \multirow{2}{*}{ Case Study } & \multicolumn{2}{|c|}{ MAPE } \\
\cline { 2 - 3 } & Temperature (Temp.) & Wind speed (W.S) \\
\hline Case 4 (Time, Pressure and Humidity) & 7.6393 & 15.3846 \\
\hline Case 5 (Time, Pressure and Dew Point) & 11.8656 & 16.6324 \\
\hline Case 6 (Time, Dew Point and Humidity) & 7.7567 & 15.4171 \\
\hline
\end{tabular}

Figure 4 shows a comparison between the actual and the forecasted values for the three cases using NARX.

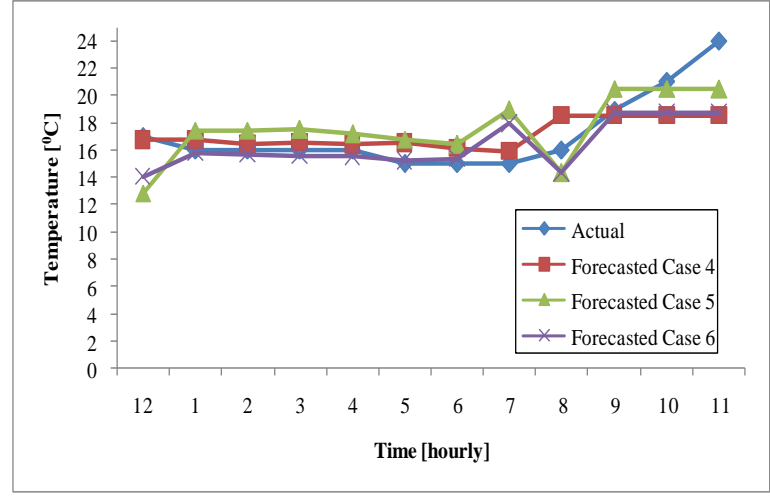

(a) Temp forecasting in the three cases

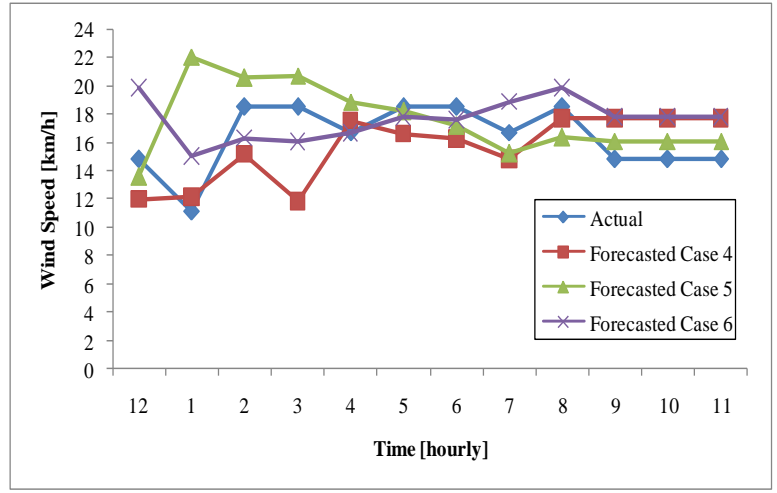

(b) Pressure forecasting in the three cases

Fig. 4: Comparison between actual and forecasted data for (a) Temp. and (b) W.S. in cases 4, 5 and 6

MAPE of the forecasting data which is shown in tables 5 and 9 indicates that it does not exceed $20 \%$. As a result NARX can be applied for forecasting metrological parameters under any conditions.

\section{CONCLUSION}

In this paper, Non Linear Autoregression neural network (NARX) is used for forecasting the temperature and wind speed. Through the execution of this system, NARX intelligent system can be efficiently model to forecast the Temp. and the W.S.. The mean absolute percentage error (MAPE) between the forecasted output and the actual output is used to check accuracy.

The results show that NARX approach for Temp. and W.S forecasting gives good results and can be considered as an alternative to traditional meteorological approaches used in measuring Temp. and W.S.. The MAPE for all the studied cases does not exceed 20\%, which indicates that NARX is able to determine the non-linear relationship that exists between the meteorological data (time, dew point, pressure and humidity) given to the system during the training phase. On that basis, NARX makes a prediction of what the temperature and wind speed would be in future in a successful manner. Finally, the developed model can be useful in decision making for meteorological parameter forecasting. 
DOI: https://dx.doi.org/10.26808/rs.ca.i8v1.07

International Journal of Computer Application (2250-1797)

Issue 8 Volume 1, January- February 2018

\section{ACKNOWLEDGEMENT}

I would like to express my gratitude to Prof. Dr. Faten Salah for supplying the technical data for this work and her support and advice during the progress of this work.

\section{REFRENCES}

1- L. Li, Y. Liu, Y. Yang and S. Han, "Short-term wind speed forecasting based on CFD pre-calculated flow fields", Proceedings of the Chinese Society of Electrical Engineering, vol. 33, 2013.

2- Men, Zhongxian, Eugene Yee, Fue-Sang Lien, Zhiling Yang and Yongqian Liu, "Ensemble nonlinear autoregressive exogenous artificial neural networks for short-term wind speed and power forecasting", International scholarly research notices, 2014.

3- D. Wang, F. Wang and X. Wang, "Multi-step-ahead combination forecasting of wind speed using artificial neural networks", Research Journal of Applied Sciences, Engineering and Technology, vol. 5, 2013.

4- E. Erdem and J. Shi, "ARMA based approaches for forecasting the tuple of wind speed and direction", Applied Energy, vol. 88, 2011.

5- J. L. Torres, A. García, M. de Blas and A. de Francisco, "Forecast of hourly average wind speed with ARMA models in Navarre (Spain)", Solar Energy, vol. 79, 2005.

6- Xie, H., H. Tang and Y.H. Liao, "Time series prediction based on NARX neural network", Proceeding of the International Conference on Machine Learning and Cybernetics, IEEE Xplore Press, vol.3, 2009.

7- I. G. Damousis and P. Dokopoulos, "A fuzzy model expert system for the forecasting of wind speed and power generation in wind farms", in Proceedings of the IEEE International Conference on Power Industry Computer Applications (PICA '01), Sydney, Australia, 2001.

8- I. G. Damousis, M. C. Alexiadis, J. B. Theocharis and P. S. Dokopoulos ", A fuzzy model for wind speed prediction and power generation in wind parks using spatial correlation," IEEE Transactions on Energy Conversion, vol. 19, 2004.

9- P. Pinson and G. N. Kariniotakis, "Wind power forecasting using fuzzy neural networks enhanced with on-line prediction risk assessment", in Proceedings of the IEEE Power Technology Conference, Bologna, Italy, vol.2, 2003.

10- J. Zeng and W. Qiao, "Support vector machine-based short-term wind power forecasting", in Proceedings of the IEEE PES Power Systems Conference and Exposition (PSCE '11), Phoenix, Arizona, 2011.

11- M. A. Mohandes, T. O. Halawani, S. Rehman and A. A. Hussain, "Support vector machines for wind speed prediction", Renewable Energy, vol. 29, 2004.

12- A. M. Foley, P. G. Leahy, A. Marvuglia and E. J. McKeogh, "Current methods and advances in forecasting of wind power generation", Renewable Energy, vol. 37, 2012.

13- Arbain, S. and A. Wibowo," Time series methods for water level forecasting of Dungun river in Terengganu Malaysia", Int. J. Eng. Sci. Technol., vol.4, 2012. 
DOI: https://dx.doi.org/10.26808/rs.ca.i8v1.07

14- Suguna, N. and K.G. Thanuskodi, "Predicting missing attribute values using K-means clustering", J. Comput. Sci., vol. 7, 2011.

15- Toriman, M.E., H. Juahir, M. Mokhtar, G.M. Barzani and S.A.S. Mastura, "Predicting for discharge characteristics in Langat River, Malaysia using neural network application model", Res. J. Earth Sci., vol.1, 2009.

16- Yazeed A. Al-Sbou1 and Khaled M. Alawasa2, "Nonlinear autoregressive recurrent neural network model for solar radiation prediction", International Journal of Applied Engineering Research, vol. 12, 2017.

17- Horne, B.G. and C.L. Giles, "An experimental comparison of recurrent neural network", 7th Edn., MIT Press, 1995.

18- Siti Hajar Arbain and Antoni Wibowo, "Neural Networks Based Nonlinear Time Series Regression for Water Level Forecasting of Dungun River", Journal of Computer Science, vol. 8, 2012.

19- Yazeed A. Al-Sbou1 and Khaled M. Alawasa, "Nonlinear autoregressive recurrent neural network model for solar radiation prediction", International Journal of Applied Engineering Research, vol.12, 2017.

20- A.Y.Hatata and M.Eladawy, "Prediction of the true harmonic current contribution of nonlinear loads using NARX neural network", Alexandria Engineering Journal, 2017.

21- Easterling and William E., "Subscribers to the NOAA monthly and seasonal weather outlook", Bulletin of the American Meteorological Society, vol.67, 1986. 